\title{
Stereopsis and spatial perception in amblyopes and uncorrected ametropes
}

\author{
WALIA KANI \\ From the Department of Psychology, University of Durham
}

SUMMARY Amblyopes and nonamblyopes were compared on 2 tests of spatial perception. One, the Titmus stereotest, provided only disparity cues and thus measured pure stereopsis. The other, the 3-rods test, provided a variety of monocular and binocular cues and measured the precision of distance discrimination. On both tests the amblyopes were significantly worse than nonamblyopes with equivalent acuity deficits. The Titmus stereotest was found to be an effective means of screening for amblyopia. The results of the distance discrimination test are discussed in terms of their clinical and physiological implications.

Perception of three-dimensional space is facilitated by a number of cues, such as accommodation, convergence (Lie, 1965), movement parallax (Johannson, 1973), apparent size, shape, overlay, perspective, and illumination gradients. In addition to these monocular cues species with overlapping visual fields can utilise the disparity information provided by the horizontal separation between their 2 eyes. A single point in space is imaged at 2 disparate points on the 2 retinae (unless it is being fixated), and the degree of disparity between the 2 retinal points is dependent on the spatial location of the point. In this paper 'depth perception' is used to refer to perception utilising any number of the cues mentioned above, and 'stereopsis' is reserved for perception of depth arising solely from disparity information. Thus stereopsis can be assessed only when all other cues have been eliminated, whereas depth perception can be assessed when any number of cues are present.

In the last 10 years considerable advances have been made in our knowledge of the neurophysiological basis of stereopsis. Cortical cells which are tuned to respond maximally to specific retinal disparities have been found in cats (Barlow et al., 1967) and sheep (Clarke et al., 1976). This specificity is present at birth in some species but not others; it has been found in sheep (Ramachandran et al., 1977) but not in cats (Pettigrew, 1974). There is evidence that normal visual experience is essential for the development of these disparity detector cells. In cats the specificity and binocularity of these cells

Address for reprints: Ms Walia Kani, Department of Psychology, University of Durham, Science Laboratories, South Road, Durham DH1 3LE can be considerably reduced by monocular deprivation during a 'critical period' which lasts from birth to 3 months (Hubel and Wiesel, 1970; Blakemore, 1976). In sheep cell specificity is present at birth, but it has been suggested (Ramachandran et al., 1977) that normal visual experience is required to enhance the binocularity of the disparity detector cells, which at birth respond to monocular stimulation.

The abundance of evidence from visual deprivation experiments on animals may parallel clinical evidence from man, in whom a monocular optical or muscular defect in early childhood precedes amblyopia. This condition is characterised by the inability of the defective eye to achieve a high visual acuity unless the causative defects are corrected before the end of a critical period. It has been suggested that, for man, this extends from birth to the end of the third year (Banks et al., 1975). Similar monocular defects occurring later in life do not give rise to amblyopia.

Another characteristic of amblyopes is their failure to perceive depth in tests of stereopsis which provide only disparity cues (Frisby et al., 1975; Reinecke and Simons, 1974; Walraven, 1975). It seems possible that they, like the experimental animals already described, lack cortical disparity detector cells, because they did not receive appropriate visual stimulation during childhood.

If amblyopes do not perceive disparity as a cue to spatial location, they must either make use of other cues or perceive the world as being two-dimensional. This study was designed to investigate these possibilities. The perceptual skills of amblyopes and nonamblyopes were compared in a task which offered cues other than disparity to aid spatial 
localisation. These additional cues included monocular cues, such as apparent size changes and luminance changes, and binocular cues such as accommodation and convegence. In addition visual acuity and stereopsis were measured in order to evaluate their contributions to spatial perception.

\section{Methods}

Subjects were selected from a population of approximately 200 undergraduates who were screened on a Snellen letter chart at $6 \mathrm{~m}$. All those who achieved unequal right-eye and left-eye acuities were refracted and examined ophthalmoscopically, and relevant details of ocular history were recorded.

Amblyopes were defined as those who could not achieve equal acuities when wearing full optical corrections. Nonamblyopes could all achieve equal acuities of $6 / 6$ or better after full optical correction. Eight amblyopes were found (7 anisometropic and 1 strabismic) none of whom had eccentric fixation by visuscopy. This proportion $(4 \%)$ is close to the incidence of amblyopia reported by other authors, for example, Sutcliffe (1960).

Sixteen nonamblyopes selected as controls were either uncorrected or undercorrected myopes or astigmats. None of them had worn their full optical corrections for at least 5 years, and they were selected on the assumption that they, like the amblyopes, would have adapted to their acuity deficits. Eight of these control nonamblyopes were selected as subjects because their acuities in both eyes closely matched the acuities of the 8 amblyopes. The other 8 control nonamblyopes were chosen because their acuities covered a wide range which would be useful in correlative procedures.

Each of the 24 subjects performed the following tests: (1) Snellen acuity test; (2) Titmus test of stereoacuity; (3) 3-rods test of depth discrimination. Half the subjects ( 4 amblyopes and 8 nonamblyopes) were used in an additional experiment (4) to investigate the importance of luminance as a cue in the 3-rods test.

\section{MEASUREMENT OF VISUAL ACUITY}

Visual acuities were measured monocularly on a standard Snellen chart at $6 \mathrm{~m}$. Acuity was recorded as the last line read faultlessly. Snellen fractions were converted to angular subtense in minutes of arc in accordance with the conventional rule that the angle subtended by a single element of the Snellen letter represents the resolution threshold. Thus $6 / 6$ is equivalent to a resolution of 1 minute of arc.

MEASUREMENT OF STEREOACUITY

Stereoacuity can be defined as a quantitative measure of stereopsis. It was assessed using the
Titmus stereotest (Titmus Optical Co. Inc., Petersburg, Virginia). Subjects wore a pair of spectacles carrying 2 mutually perpendicular Polaroid lenses which dissociated the 2 eyes. The Titmus test stimuli consisted of 10 pairs of orthogonally polarised images, so that only 1 of the pair was seen by each eye. There was a small horizontal disparity between the 2 images in each pair, and in the presence of stereopsis this disparity cue was interpreted as a depth cue. Ten different degrees of disparity were presented in the 10 test stimuli. Each stimulus (that is, pair of images) showed a cluster of 4 rings. Only 1 of the 4 included the disparity cue, which made the ring appear to stand above the plane of the background if stereopsis was present. Subjects were required to make a forced choice response to report the location of the raised ring in relation to the cluster for each of the 10 stimuli. Stereoacuity was recorded as the smallest disparity correctly interpreted as a depth cue.

\section{MEASUREMENT OF DEPTH DISCRIMINATION}

Depth discrimination was measured by the three rods test (Helmholtz, 1866). The apparatus is shown and described in Fig. 1.

In designing the 3-rods apparatus it became apparent that the central rod's position along the sagittal axis determined its luminance: as it approached the front of the box, where the light source was situated, it appeared brighter. This cue could be utilised in making alignments by matching the luminance of the mobile central rod to that of the 2 fixed rods.

To assess the effect of this cue 12 subjects performed the 3-rods test twice on 2 slightly different versions of the apparatus. One version was exactly as described in Fig. 1. The other had all interior surfaces of the box painted black; this reduced the amount of internal reflection from walls and maximised the directionality of illumination within the box.

Subjects were seated $6 \mathrm{~m}$ away from the apparatus with instructions to keep as still as possible, so that the motion parallax cue was minimised. For each trial the subject was required to align the central mobile rod with the 2 fixed rods twice. The first alignment was made by pulling the rod forwards with a single smooth movement. The position of the pointer was then recorded by the experimenter, and the subject was instructed to prepare for the second alignment by pulling the central rod right up to the front of the box. The second alignment was made by allowing the rod to regress under the weight of the pulley system, again with a single smooth movement. The new position of the pointer was recorded, and the subject was instructed to prepare for the 
next trial by allowing the rod to return to the back of the box. No time constraints were imposed on the trials. Pointer positions were recorded as errors in millimetres (that is, distance from the correct alignment position). Six trials (pairs of

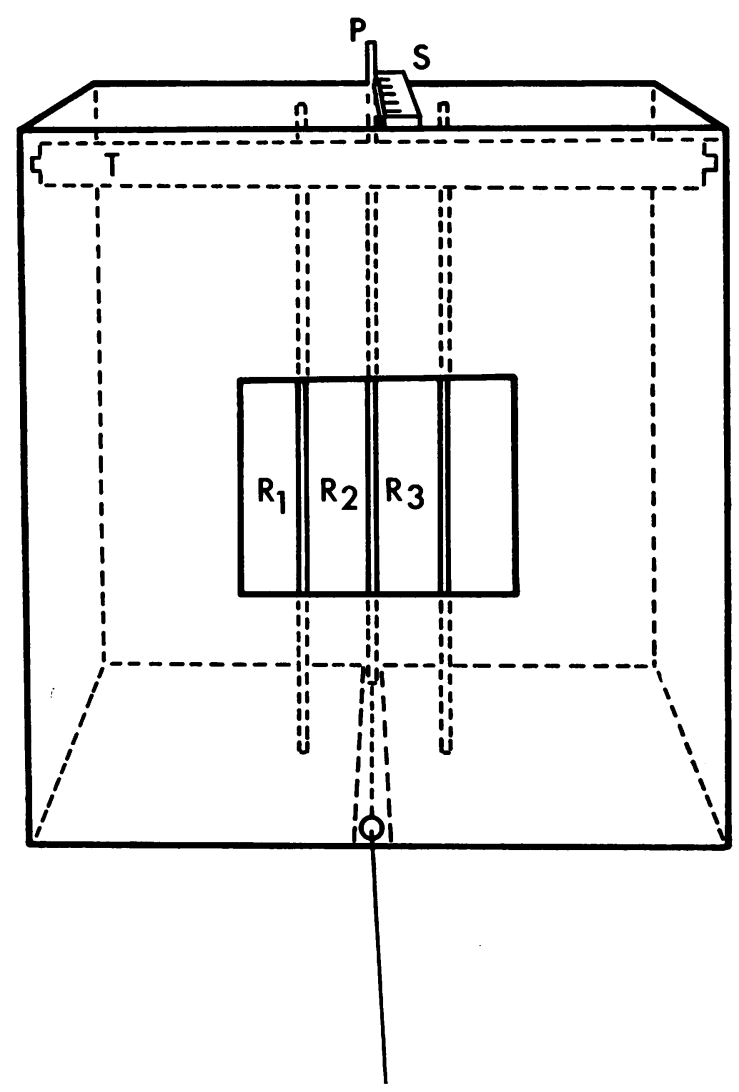

Fig. 1 Apparatus used to measure depth discrimination: 3-rods test. The two outer white rods ( $R 1$ and $R 3$ ) were fixed inside the black box $(50 \times 50 \times 70 \mathrm{~cm})$ and the central white rod $(R 2)$ was free to travel sagittally in a groove in the base of the box. The position of the central rod was indicated by the pointer $(P)$ attached to it which protruded through a slit in the top of the box. A millimetre scale $(S)$ lay along the slit so that the position of the pointer could be precisely recorded. The box was internally illuminated by a fluorescent tube $(T)$ in the upper front corner. All interior surfaces were painted white except the back wall, which was black, in order to provide a background against which the white rods could be seen. The mobile central rod was attached to a pulley system such that it could either be pulled forward by a subject, or allowed to slide backwards under the weight of the pulley system. The diagram shows the subject's view of the apparatus. The ends of the 3 rods were not visible through the rectangular frontal aperture at any time alignments) were made in each of 4 conditions in the following order:

Condition $1=$ both eyes open, room lights on (luminance 4.5 foot-lamberts). Condition $2=$ only right eye open, room lights on (luminance 4.5 footlamberts). Condition $3=$ only left eye open, room lights on (luminance 4.5 foot-lamberts). Condition $4=$ both eyes open, room lights off (luminance 0.01 foot-lamberts). Thus each subject made a total of 48 alignments.

\section{Results}

\section{VISUAL ACUITY AND STEREOACUITY}

Table 1 shows visual acuities in minutes of arc and Titmus stereoacuities in seconds of arc for all subjects. The 3 columns distinguish (1) amblyopes, (2) nonamblyopes with acuities closely matched to those of the amblyopes, and (3) other nonamblyopes. Adjacent subjects in columns 1 and 2 were treated as matched pairs for statistical purposes.

Amblyopes were significantly worse than nonamblyopes on the Titmus stereotest $(t=3 \cdot 59$, $\mathbf{P}<0.005$ ).

Fig. 2 shows the relationship between Snellen acuity of worse eye and Titmus stereoacuity.

All amblyopes failed to perceive any of the Titmus test stimuli in depth, as did one strabismic nonamblyope (24). Uncorrected myopic nonamblyopes performed well, scoring the maximum stereoacuity available. Uncorrected astigmatic nonamblyopes fell between the 2 extremes, and there is some indication that their stereoacuity correlated with their worse-eye-acuity. The dotted line in Fig. 2 indicates this correlation approximately. Quantitative evaluation is not justified in view of the small sample size.

\section{DISTANCE DISCRIMINATION MEASURED BY THE 3-RODS TEST}

Table 2 shows the errors (in centimetres) made by each subject on the white painted 3-rods apparatus. Subjects are arranged in 3 groups as in Table 1. The first 4 columns of error scores in each group's data show the means of errors made in the 12 trials in each of the 4 conditions. These are numbered 1 to 4 , as in 'Methods'. The last 2 columns for each group show the means of errors made in all 48 trials. Fig. 3 shows the errors made by the 12 subjects who were tested on both the black painted and the white painted 3-rods apparatus. Errors were significantly greater on the white painted apparatus $(t=3.04$, $P=0.01$ ).

Better eye performance was compared with worse eye performance (conditions 2 and 3). The worse eye tended to make larger errors than the better 
Table 1 Visual acuities and stereoacuities for all subjects

\begin{tabular}{|c|c|c|c|c|c|c|c|c|c|c|c|}
\hline \multicolumn{4}{|c|}{ Amblyopes } & \multicolumn{4}{|c|}{ Acuity-matched nonamblyopes } & \multicolumn{4}{|c|}{ Other nonamblyopes } \\
\hline $\begin{array}{l}\text { Subject } \\
\text { no. }\end{array}$ & $\begin{array}{l}\text { Snellen } \\
\text { acuity of } \\
\text { better eye } \\
(\text { min arc) }\end{array}$ & $\begin{array}{l}\text { Snellen } \\
\text { acuity of } \\
\text { worse eye } \\
\text { (min arc) }\end{array}$ & $\begin{array}{l}\text { Titmus } \\
\text { stereoacuity } \\
\text { (sec arc) }\end{array}$ & $\begin{array}{l}\text { Subject } \\
\text { no. }\end{array}$ & $\begin{array}{l}\text { Snellen } \\
\text { acuity of } \\
\text { better eye } \\
\text { (min arc) }\end{array}$ & $\begin{array}{l}\text { Snellen } \\
\text { acuity of } \\
\text { worse eye } \\
\text { (min arc) }\end{array}$ & $\begin{array}{l}\text { Titmus } \\
\text { stereoacuity } \\
\text { (sec arc) }\end{array}$ & $\begin{array}{l}\text { Subject } \\
\text { no. }\end{array}$ & $\begin{array}{l}\text { Snellen } \\
\text { acuity of } \\
\text { better eye } \\
\text { (min arc) }\end{array}$ & $\begin{array}{l}\text { Snellen } \\
\text { acuity of } \\
\text { worse eye } \\
\text { (min arc) }\end{array}$ & $\begin{array}{l}\text { Titmus } \\
\text { stereoacuity } \\
\text { (sec arc) }\end{array}$ \\
\hline 1 & 0.67 & $1 \cdot 5$ & $>1000$ & 9 & 0.67 & $2 \cdot 0$ & 40 & 17 & 0.67 & 0.83 & 40 \\
\hline 2 & 0.67 & $1 \cdot 5$ & 40 & 10 & 0.67 & $1 \cdot 5$ & 40 & 18 & 0.67 & $1 \cdot 0$ & 60 \\
\hline 3 & 0.67 & $3 \cdot 0$ & $>1000$ & 11 & 0.67 & $4 \cdot 0$ & 40 & 19 & 0.67 & 1.0 & 40 \\
\hline 4 & 0.83 & $1 \cdot 0$ & 400 & 12 & 0.83 & $1 \cdot 0$ & 40 & 20 & 1.0 & $4 \cdot 0$ & 60 \\
\hline 5 & 0.83 & $1 \cdot 5$ & 800 & 13 & 0.83 & $1 \cdot 0$ & 40 & 21 & 1.0 & $1 \cdot 0$ & 40 \\
\hline 6 & 0.83 & $2 \cdot 0$ & 800 & 14 & 0.83 & $2 \cdot 0$ & 40 & 22 & $1 \cdot 0$ & $1 \cdot 0$ & 80 \\
\hline 7 & $1 \cdot 5$ & $2 \cdot 0$ & $>1000$ & 15 & $1 \cdot 0$ & 1.5 & 60 & 23 & 1.0 & $2 \cdot 0$ & 200 \\
\hline 8 & $1 \cdot 5$ & 3.0 & 400 & 16 & 1.0 & $2 \cdot 0$ & 40 & 24 & $1 \cdot 5$ & $20 \cdot 0$ & $>1000$ \\
\hline
\end{tabular}

eye, but the difference was not significant $(t=0.99$, $\mathbf{P}=\mathbf{0} \cdot 2$ ). The correlation between acuity and monocular performance was also found to be insignificant (better eye, $r=0.074$; worse eye, $r=0 \cdot 117$ ). The possibility that the level of room illumination provided a luminance cue was assessed by comparing

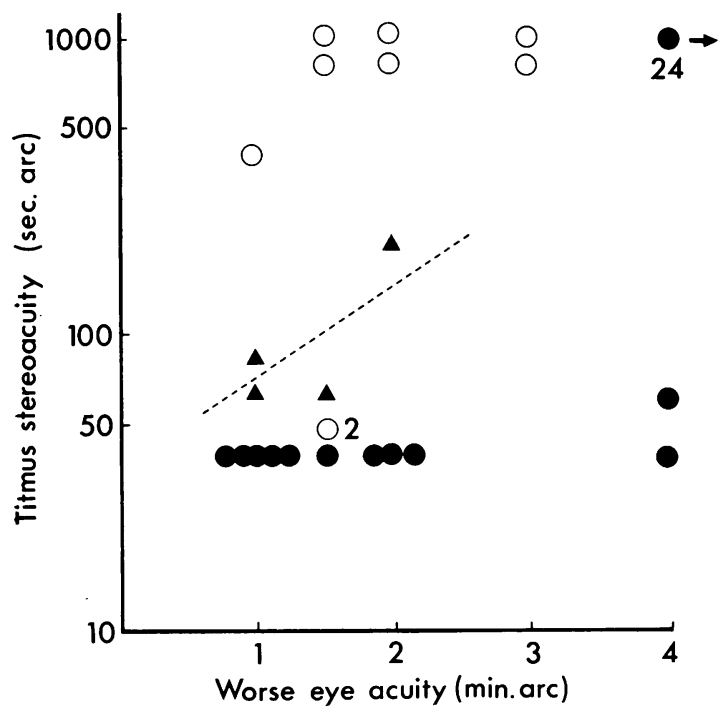

Fig. 2 Comparison of Snellen acuity of worse eye with Titmus stereo-acuity. $=$ uncorrected myopic nonamblyopes. $\mathbf{\Delta}=$ uncorrected astigmatic nonamblyopes. $\bigcirc=$ amblyopes. $24=$ a nonamblyope with alternating eostropia. $2=$ a subject who was classified as an amblyope by the acuity criterion (see 'Methods'). She later obtained a contact lens correction for irregular astigmatism which equalised her acuities; thus her original classification was shown to be wrong performances in conditions 1 and 4; they were not significantly different $(t=0 \cdot 009, \mathrm{P} \gg 0 \cdot 3)$.

Each subject's better binocular performance was compared with his better monocular performance (condition 1 or 4 compared with 2 or 3 ). Errors in centimetres are shown in Fig. 4.

Binocularity improved performance significantly for amblyopes $(t=16.53, \mathrm{P}<0.005)$ and for nonamblyopes $(t=2 \cdot 15, \mathrm{P}=0 \cdot 25)$. The amount of improvement from binocularity, that is, the reduction in error, was calculated for amblyopes and their acuity-matched nonamblyopic counterparts. A comparison of these improvement scores showed no significant differences $(t=0 \cdot 79, \mathrm{P}=0 \cdot 25)$.

Fig. 5 shows the error scores of amblyopes and their acuity-matched nonamblyopic counterparts. Amblyopes' errors were significantly greater ( $t=$ $2 \cdot 39, \mathrm{P}=0 \cdot 025$ ).

\section{Discussion}

Two perceptual capacities have been measured: distance discrimination when several cues are presented, and stereopsis when all cues except disparity are eliminated. Neither of these capacities was found to be simply determined by visual acuity, and yet both capacities were significantly reduced in amblyopes (Figs. 2 and 5). Before considering the implications of these 2 findings the results will be examined in greater detail.

\section{VISUAL ACUITY AND STEREOACUITY}

The inability of amblyopes and strabismics to perceive the disparity cues in the Titmus stereotest (Fig. 2) has been shown previously (Reinecke and Simons, 1974). A correlation between visual acuity and stereoacuity has also been previously reported 
Table 2 Results of the 3-rods test of distance discrimination. Mean errors (in $\mathrm{cm}$ ) for each of the 4 test conditions (as defined under 'Methods') and overall conditions are shown for each subject. Subjects are listed in the same order as in Table 1

\begin{tabular}{|c|c|c|c|c|c|c|c|c|c|c|c|c|c|c|c|c|c|}
\hline \multicolumn{6}{|c|}{ Amblyopes } & \multicolumn{6}{|c|}{ Nonamblyopic acuity matches } & \multicolumn{6}{|c|}{ Nonamblyopes } \\
\hline \multicolumn{4}{|c|}{$\begin{array}{l}\text { Three-rods test errors } \\
\text { (mean of } 12 \text { trials for } \\
\text { each condition in } \mathrm{cm} \text { ) }\end{array}$} & \multirow{2}{*}{$\begin{array}{l}\text { Mean of } \\
48 \text { trials } \\
(\mathrm{cm})\end{array}$} & \multirow[t]{2}{*}{$\begin{array}{l}\text { Mean of } \\
48 \text { trials } \\
\text { (sec arc) }\end{array}$} & \multicolumn{4}{|c|}{$\begin{array}{l}\text { Three-rods test errors } \\
\text { (mean of } 12 \text { trials for } \\
\text { each condition in } \mathrm{cm} \text { ) }\end{array}$} & \multirow[t]{2}{*}{$\begin{array}{l}\text { Mean of } \\
48 \text { trials } \\
(\mathrm{cm})\end{array}$} & \multirow[t]{2}{*}{$\begin{array}{l}\text { Mean of } \\
48 \text { trials } \\
\text { (sec arc) }\end{array}$} & \multicolumn{4}{|c|}{$\begin{array}{l}\text { Three-rods test errors } \\
\text { (mean of } 12 \text { trials for } \\
\text { each condition in } \mathrm{cm} \text { ) }\end{array}$} & \multirow[t]{2}{*}{$\begin{array}{l}\text { Mean of } \\
48 \text { trials } \\
(\mathrm{cm})\end{array}$} & \multirow[t]{2}{*}{$\begin{array}{l}\text { Mean of } \\
48 \text { trials } \\
\text { (sec arc) }\end{array}$} \\
\hline C.1 & C.2 & C.3 & $C .4^{*}$ & & & $C .1$ & C.2 & $C .3$ & $C .4$ & & & C.1 & C.2 & C.3 & $C .4$ & & \\
\hline $11 \cdot 70$ & $12 \cdot 30$ & $10 \cdot 07$ & $8 \cdot 89$ & $10 \cdot 74$ & $36 \cdot 5$ & $2 \cdot 11$ & $4 \cdot 73$ & $3 \cdot 22$ & $1 \cdot 18$ & $2 \cdot 81$ & $9 \cdot 6$ & $2 \cdot 77$ & $2 \cdot 84$ & $2 \cdot 74$ & $3 \cdot 07$ & $2 \cdot 86$ & $9 \cdot 7$ \\
\hline 0.93 & $5 \cdot 49$ & $5 \cdot 53$ & $1 \cdot 18$ & $3 \cdot 28$ & $11 \cdot 2$ & $2 \cdot 27$ & 3.04 & 3.05 & 3.46 & $2 \cdot 96$ & $10 \cdot 1$ & 3.09 & $4 \cdot 64$ & $9 \cdot 24$ & $4 \cdot 23$ & 5.03 & $17 \cdot 1$ \\
\hline 3.65 & $5 \cdot 86$ & $4 \cdot 84$ & 3.95 & $4 \cdot 58$ & $15 \cdot 6$ & $2 \cdot 11$ & $6 \cdot 37$ & 1.97 & $4 \cdot 23$ & 3.67 & $12 \cdot 5$ & $2 \cdot 36$ & 2.43 & $3 \cdot 18$ & 2.04 & 2.49 & 8.5 \\
\hline $2 \cdot 33$ & 3.43 & $4 \cdot 83$ & $4 \cdot 36$ & $3 \cdot 74$ & $12 \cdot 7$ & $2 \cdot 29$ & $4 \cdot 21$ & 5.09 & 3.01 & 3.65 & $12 \cdot 4$ & $7 \cdot 38$ & $2 \cdot 29$ & $5 \cdot 63$ & $4 \cdot 83$ & 5.03 & $17 \cdot 1$ \\
\hline 4.49 & $6 \cdot 18$ & $7 \cdot 76$ & 4.98 & $5 \cdot 85$ & 19.9 & $6 \cdot 23$ & $7 \cdot 28$ & 6.48 & 3.88 & 6.00 & $20 \cdot 4$ & $7 \cdot 18$ & $7 \cdot 101$ & 14.94 & $4 \cdot 60$ & $8 \cdot 46$ & $28 \cdot 8$ \\
\hline $5 \cdot 39$ & $9 \cdot 15$ & $7 \cdot 68$ & 2.44 & $6 \cdot 17$ & $21 \cdot 0$ & 0.71 & $1 \cdot 76$ & $2 \cdot 75$ & 1.95 & $1 \cdot 79$ & $6 \cdot 1$ & $1 \cdot 27$ & 3.86 & $5 \cdot 37$ & $1 \cdot 80$ & 3.09 & $10 \cdot 5$ \\
\hline $5 \cdot 11$ & 5.98 & 5.96 & $2 \cdot 44$ & $4 \cdot 87$ & $16 \cdot 6$ & $2 \cdot 13$ & 3.65 & $1 \cdot 53$ & 3.62 & $2 \cdot 73$ & $9 \cdot 3$ & $3 \cdot 73$ & $2 \cdot 24$ & 3.39 & $4 \cdot 10$ & $3 \cdot 37$ & $11 \cdot 5$ \\
\hline
\end{tabular}

*Conditions $1,2,3$, and 4 (see text)

(Levy and Glick, 1974), but the high performance of the nonamblyopic myopes appears to conflict with this correlation. However, it can be explained by the fact that the Titmus test was conducted at a distance of $30 \mathrm{~cm}$; at this distance myopia of less than 3 DS would have no effect on visual acuity. None of the nonamblyopic myopes exceeded this 3 DS limit.

\section{DISTANCE DISCRIMINATION}

Fig. 3 shows that luminance was an important cue facilitating precision in the black painted 3-rods apparatus. Increasing the internal reflections by painting the interior surfaces white reduced this cue considerably, and precision of alignment was correspondingly worse. Binocularity proved to be of considerable advantage to all subjects (Fig. 4). Some of the improvement attained with binocularity can be attributed to the retinal disparity cue, but this explanation is applicable only in the case of nonamblyopic subjects. Amblyopic subjects were unable to perceive any of the disparity cues in the Titmus stereotest, and so it seems unlikely that they could make use of them in the 3-rods test when the angular disparities were much smaller. Amblyopes must therefore have made use of other cues provided by binocularity, for example, proprioceptive information from accommodation and convergence.

COMPARISON OF STEREOPSIS AND

DISTANCE DISCRIMINATION

Fig. 6 shows the relationship between distance discrimination measured as angular errors on the 3-rods test and Titmus stereoacuity measured as angular disparities detected. All subjects made smaller errors on the 3-rods test than their performance on the Titmus stereotest would have predicted. Hence all points lie to the right of the dotted line, which represents equivalent disparities on the 2 tests. The presence of cues additional to disparity must account for this finding. The horizontal

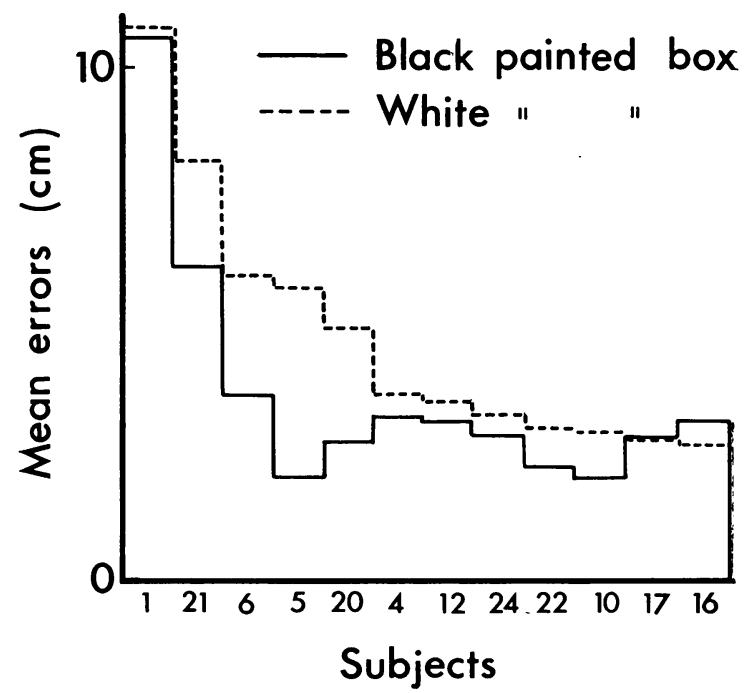

Fig. 3 Comparison of performance on the black painted 3-rods apparatus with performance on the white painted version. Mean errors over all 48 trials are shown for 12 subjects 
Fig. 4 Comparison of monocular performance with binocular performance for each subject. The solid lines show each subject's smaller binocular error (that is, performance in condition 1 or 4). The dotted lines show smaller monocular error (that is, performance in condition 2 or 3 )

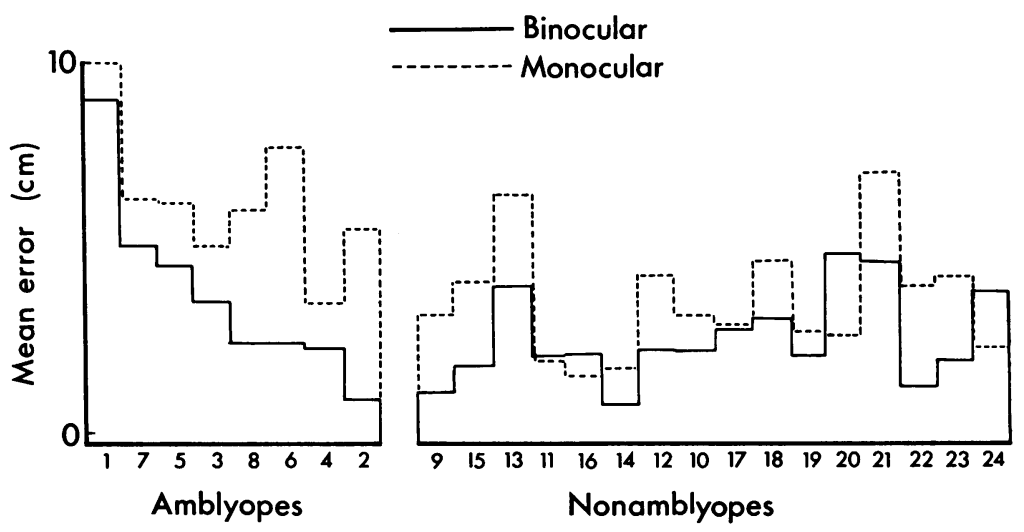

ing amblyopia and strabismus has been confirmed. The 3-rods test, on the other hand, provides more descriptive information about the perceptual abilities of subjects in an environment offering a variety of spatial cues. The Titmus test provides a pure measure of stereopsis, whereas the 3-rods test measures the precision of spatial perception in functional terms.

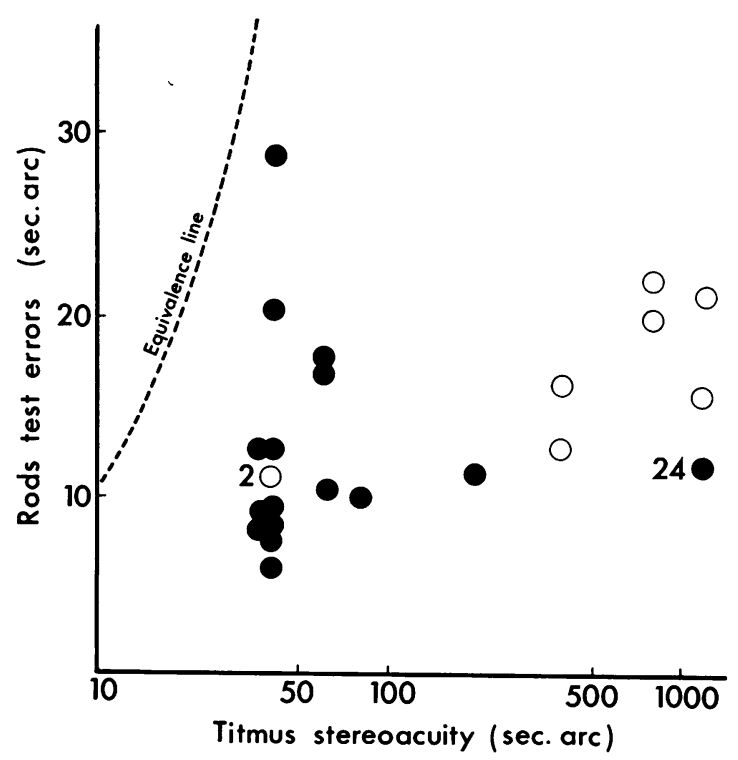

Fig. 6 Comparison of results obtained from 2 tests of spatial perception. Errors made on the 3-rods test of distance discrimination are plotted vertically on a linear scale of angular subtense in seconds of arc. Disparities just detected on the Titmus stereotest are plotted horizontally on a logarithmic scale of angular subtense in seconds of arc. The dotted line shows the locus of equivalent angular scores. $O=$ amblyopes.

= non-amblyopes. 2 and 24 are explained in Fig. 2
CLINICAL IMPLICATIONS

The value of the Titmus test as a method for detect- 
The amblyopic group's mean error of $5 \mathrm{~cm}$ at a testing distance of $6 \mathrm{~m}$ corresponds to an error of $15 \mathrm{yd}(14 \mathrm{~m})$ at a mile. This represents an order of accuracy which is adequate for most perceptual tasks normally encountered, with the exception of those in which high speed or unusual surroundings necessitate greater precision. The results of the 3rods test confirm that, despite their lack of stereopsis, the perceptual world of amblyopes is definitely three-dimensional.

\section{PHYSIOLOGICAL IMPLICATIONS}

Lack of stereopsis has been attributed to the absence of the cortical disparity detection mechanism (Blakemore and van Sluyters, 1974). Various animal studies have shown that abnormal early visual experience can cause changes in the binocularity of cortical function. Amblyopes and strabismics suffer abnormal early visual experience as a result of their optical or muscular defects, and they have been shown, by performance of the Titmus test, to lack stereopsis based on disparity detection alone. Thus it seems possible that they lack binocular function at a cortical level. However, their ability to benefit from binocularity in the 3-rods test (Fig. 4) suggests that they may retain proprioceptive functions mediated by accommodation and convergence. The pathways involved in these proprioceptive functions are not known.

Hochberg (1972) reviewed studies of accommodation and convergence as spatial cues and concluded that they are usually extremely weak cues. Perhaps amblyopes learn to make better use of them in order to compensate for their inability to detect disparity cues. This possibility could be investigated by comparing amblyopes and acuity-matched nonamblyopes on a task presenting only proprioceptive information. Such a comparison would also provide some information about the pathways of proprioception.

\section{References}

Banks, M. S., Aslin, R. N., and Letson, R. D. (1975). Sensitive period for the development of human binocular vision. Science, 190, 675-677.

Barlow, H. B., Blakemore, C., and Pettigrew, J. D. (1967). The neural mechanism of binocular depth perception. Journal of Physiology, 193, 327-342.

Blakemore, C. (1976). The conditions required for the maintenance of binocularity in the kitten's visual cortex. Journal of Physiology, 261, 432-444.

Blakemore, C., and van Sluyters, R. C. (1974). Experimental analysis of amblyopia and strabismus. British Journal of Ophthalmology, 58, 176-182.

Clarke, P. G. H., Donaldson, L. M. L., and Whitteridge, D. (1976). Binocular visual mechanisms in cortical areas 1 and 2 of the sheep. Journal of Physiology, 256, 509-526.

Frisby, J. P., Mein, J., Saye, A., and Stanworth, A. (1975). Use of random-dot stereograms in the clinical assessment of strabismic patients. British Journal of Ophthalmology, 59, 545-552.

Helmholtz, H. (1896). Die einfachen Farben. In Handbuch der physiologischen Optik, vol. 2, p. 306. Edited by J. P. C. Southall. Dover Publications Inc.

Hochberg, J. (1972). Visual depth perception. In Woodworth and Schlosberg's Experimental Psychology, pp. 477-480. Edited by J. W. Kling and L. A. Riggs. Methuen: London.

Hubel, D. H., and Wiesel, T. N. (1970). The period of susceptibility to the physiological effects of unilateral eye closure in kittens. Journal of Physiology, 206, 419-436.

Johansson, G. (1973). Monocular movement parallax and near-space perception. Perception, 2, 135-146.

Levy, B. S., and Glick, E. B. (1974). Stereoscopic perception and Snellen visual acuity. American Journal of Ophthalmology, 78, 722-724.

Lie, I. (1965). Convergence as a cue to perceived size and distance. Scandinavian Journal of Psychology, 6, 109-116.

Pettigrew, J. D. (1974). The effect of visual experience on the development of stimulus specificity by kitten cortical neurones. Journal of Physiology, 237, 49-74.

Ramachandran, V. S., Clarke, P. G. H., and Whitteridge, D. (1977). Cells selective to binocular disparity in the cortex of newborn lambs. Nature, 268, 333-335.

Reinecke, R. D., and Simons, K. (1974). A new stereoscopic test for amblyopia screening. American Journal of Ophthalmology, 78, 714-721.

Sutcliffe, S. (1960). Visual screening of three year old children. British Orthoptic Journal, 17, 1-11.

Walraven, P. L. (1975). Amblyopia screening with random dot stereograms. American Journal of Ophthalmology, 80, 893-900. 